4 Sowers JR, Hershmann JM, Carlson HE, et al. Effect of human chorionic gonadotrophin on thyroid function in euthyroid man. $\mathcal{F}$ Clin Endocrinol Metab 1978;47:895-8.

5 Norman RJ, Lowrings C, Oliver T, et al. Doubts about human chorionic gonadotrophin as a thyroid stimulator. Lancet 1985; i: 1096.

(Accepted 1 October 1987)

Departments of Endocrinology and Reproductive Biology, University Hospital of the Vrije Universiteit Brussel, Brussels, Belgium

M NOPPEN, MD, assistant

$B$ VELKENIERS, $M D$, internist

P BUYDENS, $M D$, internist

P DEVROEY, MD, gynaecologist

A VAN STEIRTEGHEM, MD, PHD, head, radioimmunoassay department

L VANHAELST, MD, PHD, head, endocrinology department

Correspondence to: Dr M Noppen, Department of Internal Medicine, AZ-VUB, Laarbeeklaan 101, B-1090 Brussels, Belgium.

\section{Importance of negative result of cervical biopsy directed by colposcopy}

Treatment is not recommended for patients with cervical intraepithelial neoplasia unless the lesion has been assessed colposcopically. ${ }^{1}$ The aim of our study was to examine the accuracy of cervical punch biopsy directed by colposcopy in excluding disease.

\section{Patients, methods, and results}

We reviewed the records of all patients referred to the colposcopy clinic at Birmingham and Midland Hospital for Women from March 1984 to October 1985 for investigation of persistent cytological abnormalities of the cervix. At the initial visit patients were assessed by colposcopy and a cervical smear and punch biopsy specimen were taken. In 132 patients the initial biopsy did not confirm the presence of disease. These patients were reviewed at intervals of four months and further smears and biopsies performed as necessary. Four groups with the following characteristics were identified.

Group $1(\mathrm{n}=51)$ - A histological abnormality was seen in a subsequent punch biopsy specimen.

Group $2(n=65)$-Subsequent cervical smears showed no abnormality; the median follow up period was 14 months and the median number of follow up smears per patient was two. Initial smears showed no abnormality in 31 patients.

Group $3(\mathrm{n}=8)$ - The cytological abnormality continued. A further punch biopsy yielded negative results in five cases.

Group $4(\mathrm{n}=8)$ - These patients underwent cone biopsy because of persistent unexplained cytological abnormality (six) or a predicted glandular lesion of the cervix (two). In the patients with an unexplained abnormality histological

Comparison of cytological findings on day of initial punch biopsy in patients who did and did not have abnormality at subsequent examinations

\begin{tabular}{lcrrrrrr}
\hline \multicolumn{7}{c}{ Cytological findings $^{\star}$} \\
\hline $\begin{array}{c}\text { No abnor- } \\
\text { mality }\end{array}$ & Atypical & IIIa & IIIb & IV & Total \\
\hline Outcome & 12 & 5 & 12 & 12 & 14 & 55 \\
Subsequent positive histological & 31 & 6 & 17 & 9 & 2 & 65 \\
$\begin{array}{l}\text { Negative findings at follow up smear } \\
\text { Notal }\end{array}$ & 43 & 11 & 29 & 21 & 16 & 120
\end{tabular}

*Atypical=Cellular atypia not amounting to mild dyskaryosis. IIIa= Mildly dyskaryotic cells suggesting cervical intraepithelial neoplasia Grade I. IIIb=Moderately dyskaryotic cells suggesting cervical intraepithelial neoplasia Grade 2 . IV=Severely dyskaryotic cells or cells that appear malignant, suggesting cervical intraepithelial neoplasia Grade 3. examination of the biopsy specimen showed cervical intraepithelial neoplasia grade III (one patient), adenocarcinoma in situ (one), adenocarcinoma in situ with cervical intraepithelial neoplasia grade III (one), and no abnormalities (three). In the two further patients histological examination showed mild cervical glandular atypia in one and no abnormalities in the other.

\section{Comment}

We found that 55 of 132 women in whom an initial punch biopsy gave a negative result had a cervical lesion on repeat biopsy. Absence of histological abnormalities at the initial screening may be due to a false positive result for the referral smear, a false negative result for the initial biopsy, or spontaneous regression of a cytological abnormality. A false positive result was unlikely as only patients with a history of persistent cytological abnormality were seen. False negative results of biopsy may result from inaccurate sampling of a small lesion or one located in the lower part of the endocervical canal or from the pathologist overlooking a lesion if the tissue has not been completely sectioned after initial histological assessment has given a negative result. A true negative biopsy result would occur if the lesion had regressed spontaneously before colposcopy.

Spontaneous regression of cytological abnormalities is well recognised ${ }^{23}$ and seems to have occurred in the 31 patients in group 2 in whom cytological and histological examination on the day of the initial assessment and subsequent cytological review did not show any abnormality. In these cases the colposcopist probably misinterpreted inflammation or immature metaplasia as intraepithelial neoplasia when selecting the area for biopsy. The 34 cases in group 2 in which cytological examination showed abnormalities on the day of the initial punch biopsy but subsequently yielded negative results are difficult to explain. This might occur if the biopsy removed the whole lesion but the pathologist did not detect it or if the colposcopist failed to obtain a specimen of the lesion, which then regressed spontaneously before the next smear was taken. The rate of false negative results would decrease if the colposcopist took multiple specimens, but we disagree with this policy because it would lead to an increase in morbidity and laboratory workload and almost certainly to a less critical colposcopic assessment.

The cervical smear taken on the day of initial colposcopy was of limited value in predicting the final outcome (table). We emphasise, therefore, the importance of follow up examinations in patients referred because of cytological abnormality in whom the initial biopsy directed by colposcopy does not confirm the presence of disease.

We thank Mrs Joan Sharp for her help in collecting the data.

1 Jordan JA, Sharp F, Singer A, eds. Pre-clinical neoplasia of the cervix. Proceedings of the ninth study group of the Royal College of Obstetricians and Gynaecologists. London: Royal College of group of the Royal College of Obstetricians

2 Nasiell K, Nasiell M, Vaclavinkova V. Behavior of moderate cervical dysplasia during long term follow-up. Obstet Gynecol 1983;61:609-14.

3 Nasiell K, Roger V, Nasiell M. Behavior of mild cervical dysplasia during long term follow-up. Obstet Gynecol 1986;67:665-9.

(Accepted 1 October 1987)

Birmingham and Midland Hospital for Women, Birmingham B11 4HL PAUL BYRNE, MB, MRCOG, clinical research fellow JOSEPH JORDAN, MD, FRCOG, consultant obstetrician and gynaecologist

Department of Obstetrics and Gynaecology, Birmingham Maternity Hospital, Birmingham B15 2TG

DENNIS WILLIAMS, FIMLS, chief medical laboratory scientific officer

Department of Social Medicine, Medical School, Birmingham B15 2TJ CIARAN WOODMAN, MB, MRCOG, registrar

Correspondence to: Dr P Byrne, Pathology Laboratory, Warwick Hospital, Warwick CV34 5BJ. 